\title{
Assessing Strong Consistency of Symmetrical Solid-state Supercapacitors Based on Three- dimensional Porous Carbon Material
}

\section{P.A. Le}

Institute of Sustainability Science, Vietnam Japan University, Vietnam National University-Hanoi, Hanoi, Vietnam

\section{Van Qui Le}

Laboratory of Advanced Materials Chemistry, Advanced Institute of Materials Science, Ton Duc Thang University, Ho Chi Minh, Vietnam. Faculty of Applied Sciences, Ton Duc Thang University, Ho Chi Minh, Vietnam

\section{Thi Viet Bac Phung ( $\nabla$ ptv.bac@vju.ac.vn )}

Institute of Sustainability Science, Vietnam Japan University, Vietnam National University-Hanoi, Hanoi, Vietnam https://orcid.org/0000-0001-7717-2538

\section{Nghia Trong Nguyen}

School of Chemical Engineering, Hanoi University of Science and Technology, Hanoi, Vietnam

\section{Research}

Keywords: Biomass, highly porous carbon, peanut shell, carbonization, symmetrical solid state supercapacitors.

Posted Date: August 19th, 2021

DOI: https://doi.org/10.21203/rs.3.rs-795870/v1

License: (c) (i) This work is licensed under a Creative Commons Attribution 4.0 International License. Read Full License 


\section{Abstract}

Three-dimensional (3D) porous carbon material enhances the electrochemical performance of symmetrical solid-state supercapacitors which are prepared by using abundant biomass waste as electrodes and $\left(\mathrm{PVA}-\mathrm{Li}_{2} \mathrm{SO}_{4}\right)$ gel polymer electrolyte. A saving and simple carbonization method with $\mathrm{KOH}$ chemical activation is developed for synthesizing highly porous carbon from peanut shell with high specific surface area of $1348 \mathrm{~m}^{2} \mathrm{~g}^{-1}$, which can be reused the chemical activation solution. The electrodes making by such three-dimensional porous carbon in a $1 \mathrm{M} \mathrm{Li}_{2} \mathrm{SO}_{4}$ electrolyte demonstrates a maximum specific capacitance of $386 \mathrm{~F} \mathrm{~g}^{-1}$ at current density of $2 \mathrm{~A} \mathrm{~g}^{-1}$, energy density and power density of $53.61 \mathrm{Wh} \mathrm{k} \mathrm{g}^{-1}$ and $1000 \mathrm{~W} \mathrm{~kg}^{-1}$, respectively. The symmetrical solid state supercapacitors with sandwich structure of (3D porous carbon $\mathrm{P} / \mathrm{PVA}-\mathrm{Li}_{2} \mathrm{SO}_{4} / 3 \mathrm{D}$ porous carbon $\mathrm{P}$ ) exhibits a maximum specific capacitance of $116 \mathrm{~F} \mathrm{~g}^{-1}$ at current density of $0.5 \mathrm{~A} \mathrm{~g}^{-1}$. The energy density and power density are the value of $9 \mathrm{~W} \mathrm{~h} \mathrm{~kg}^{-1}$ and $380 \mathrm{~W} \mathrm{~kg}^{-1}$, respectively. Further, the supercapacitors also demonstrate good cycling stability $89 \%$ retention after 7000 cycles.

\section{Introduction}

The biomass materials are gradually replacing fossil fuels to become the promising materials in the context of exhausted fossil fuels. Nowadays, the biomass derived porous carbon is centrally researched for energy storage as fuel cell, batteries and supercapacitors due to abundant source, easy harvesting and stable output [1-5]. Among them, the porous carbon materials for the electrodes in the supercapacitors have attracted intensive research recently due to replace the commercial activated carbon from charcoal with low conductivity, low specific surface area and negative effects on the environment. Obviously, biomass derived porous carbon emerges are a new promising direction [6-10].

Currently, Le et al [5] reported highly activated carbon from areca palm leaves by carbonization with $\mathrm{KOH}$ pretreatment. They reached a good performance, including high surface area of $876 \mathrm{~m}^{2} \mathrm{~g}^{-1}$, high specific capacitance of $356 \mathrm{~F} \mathrm{~g}^{-1}$ in a $6 \mathrm{M} \mathrm{KOH}$ electrolyte. Besides, the porous carbon from pomelo peel fiber exhibited specific surface area of $38.44 \mathrm{~m}^{2} \mathrm{~g}^{-1}$, and specific capacitance of $141 \mathrm{~F} \mathrm{~g}^{-1}$ at current density of $0.5 \mathrm{~A} \mathrm{~g}^{-1}$ in a $1 \mathrm{M} \mathrm{Li}_{2} \mathrm{SO}_{4}$ electrolyte [6]. A hierarchical porous carbon microtubes from willow catkins reached a maximum specific surface area of $1775.7 \mathrm{~m}^{2} \mathrm{~g}^{-1}$, and capacitance of $292 \mathrm{~F} \mathrm{~g}^{-1}$ at $1 \mathrm{~A} \mathrm{~g}^{-1}$ [8]. However, most of previous carbon source depend on the harvesting-season in some of tropical countries. Besides, the specific surface area and the porous structure can be further improved by modify the processing method to prepare biomass-derived carbon. Moreover, in previous reports, the precursors were mixed directly with chemical activator, such as $\mathrm{KOH}[5,6,8]$, molten salts $\left(\mathrm{Na}_{2} \mathrm{CO}_{3}-\mathrm{K}_{2} \mathrm{CO}_{3}\right)$ [7], etc. to obtain a homogeneous mixture. This strategy has one drawback of wasting chemical and high cost. Herein, we would like to provide a good strategy to solve this problem by using the chemical activated solution and this activated solution can be reused after activation process. 
In this report, the peanut shell, one of abundant agriculture waste is used as the carbon source to prepare porous carbon material. Such raw material was pretreated by $\mathrm{KOH}$ solution and then carbonized at $800^{\circ} \mathrm{C}$ to provide excellent porous structure carbon (carbon $\mathrm{P}$ ). The 3D porous carbon $\mathrm{P}$ reaches a high specific surface area of $1348 \mathrm{~m}^{2} \mathrm{~g}^{-1}$. Employing carbon $\mathrm{P}$ for supercapacitors electrodes, it shows a good performance of high specific capacitance of $386 \mathrm{~F} \mathrm{~g}^{-1}$ and high energy density of $53.61 \mathrm{~W} \mathrm{~h} \mathrm{~kg}^{-1}$ at power density of $1000 \mathrm{~W} \mathrm{~kg}^{-1}$ in electrolyte of $1 \mathrm{M} \mathrm{Li}_{2} \mathrm{SO}_{4}$. The symmetrical solid state supercapacitors made by 3D porous carbon $P$ as both electrodes exhibits high electrode specific capacitance of $116 \mathrm{~F} \mathrm{~g}^{-1}$ and energy density of $9.06 \mathrm{Wh} \mathrm{kg}^{-1}$ at power density of $380 \mathrm{~W} \mathrm{~kg}^{-1}$.

\section{Experimental}

\subsection{Preparation of porous carbon and characterizations}

The peanut shell was collected from Vietnam night market. The peanut shell was washed and cleaned by distilled water, dried at $60^{\circ} \mathrm{C}$ for 5 days to reach a constant weight. Then, $2.5 \mathrm{~g}$ peanut shells were impregnated in $100 \mathrm{ml} 1 \mathrm{M} \mathrm{KOH}$ for $24 \mathrm{~h}$ and dried at $80^{\circ} \mathrm{C}$ for $6 \mathrm{~h}$. These pretreated-shells were carbonized in industry anaerobic furnace for $1 \mathrm{~h}$ at standard temperature of $800^{\circ} \mathrm{C}$. After cooling down to room temperature, the product was washed carefully with $10 \% \mathrm{HCl}$, subsequently distilled water, and ethanol to remove residual substances and then dried in vacuum oven at $100^{\circ} \mathrm{C}$ for $24 \mathrm{~h}$ to obtain the final porous carbon product named carbon P.

Herein, we would like to introduce one amazing key point in this research: the precursor (peanut shell) was immersed in solution $\mathrm{KOH} 1 \mathrm{M}$ as the chemical activator for next step, and after that this $\mathrm{KOH}$ solution can be reused for the next batch.

The 3D porous carbon P powder was studied by many methods, such as X-ray diffraction (XRD, Bruker D2 with a Cu Ka tube), Raman spectra (Jobin Won, Horiba, Ar laser source with excitation wavelength of 520 $\mathrm{nm}$ ), scanning electron microscope (SEM, Hitachi SU8000, accelerating voltage of $15 \mathrm{kV}$ ), transmission electron microscopy (TEM, Joel-JEM-2100F, accelerating voltage of $200 \mathrm{kV}$ ), X-ray photoelectron spectroscopy (XPS, Auger Electron Spectroscopy, Microlab 350). The Brunauer-Emmett-Teller (BET) with nitrogen adsorption and desorption isotherms were tested by specific surface area and porosity analyzer (Micromeritics, ASAP 2020). The Fourier-transform infrared spectroscopy (FTIR, Jasco, UK) was performed to obtain the structure of chemical group. Thermal gravimetric analysis (TGA) was examined with thermogravimetric analyzer (Star System, Mettler Toledo).

\subsection{Preparation of electrode and electrochemical characterization}

For preparing three electrode system, the active materials (carbon $\mathrm{P}$ or charcoal activated or carbon black; $8 \mathrm{mg}$ ) were mixed with CNT $(1 \mathrm{mg})$ and PVDF $(1 \mathrm{mg})$ and dissolved in $0.2 \mathrm{ml} \mathrm{NMP} \mathrm{solution} \mathrm{to} \mathrm{obtain} \mathrm{the}$ black slurries. These three black slurries were coated on carbon paper substrates $(1 \mathrm{~cm} \times 2 \mathrm{~cm})$, 
respectively and dried to obtain $2 \mathrm{mg}$ per $2 \mathrm{~cm}^{2}$ as working electrodes. The platinum foil $(1 \mathrm{~cm} \times 2 \mathrm{~cm})$ is considered as counter electrode and $\mathrm{Ag} / \mathrm{AgCl}$ reference electrode. Herein, $\mathrm{Li}_{2} \mathrm{SO}_{4} 1 \mathrm{M}$ is an aqueous electrolyte.

Moreover, for comparison, we compare our highly 3D porous carbon derived from peanut shell (Carbon P) with two commercial carbon products: charcoal activated powder (Showa, Japan) and carbon black (Alfar Aesar).

For fabrication symmetrical solid state supercapacitors (SSCs), the 3D porous carbon P slurry was coated on carbon papers $(1 \mathrm{~cm} \times 2 \mathrm{~cm})$ and dried to reach the mass of $2 \mathrm{mg}$ for each electrode (include binder) as both anode and cathode. A gel polymer electrolyte (GPE) of PVA-KOH was prepared by solution mixing method: $1 \mathrm{~g}$ PVA and $1 \mathrm{~g} \mathrm{Li}_{2} \mathrm{SO}_{4}$ were mixed with $20 \mathrm{ml}$ distilled water and stirred at $100^{\circ} \mathrm{C}$ for $4 \mathrm{~h}$ to obtain homogenous gel solution. The symmetrical SSCs devices were fabricated as sandwich structure: one layer GPE between two layers of the electrodes.

The electrochemical measurements of the supercapacitors and electrode including CV, EIS and GCD were carried out by electrochemical workstation (Zahner Zenium, Germany). For obtaining the value of the specific capacitance $\left(\mathrm{F} \mathrm{g}^{-1}\right)$ from the GCD curve, the calculation equation $[4,5]$ is:

$$
\mathrm{C}=\frac{\mathrm{I} \Delta \mathrm{t}}{\mathrm{m} \Delta \mathrm{V}}
$$

where I (A) is the discharge current, $\Delta \mathrm{t}(\mathrm{s})$ is the discharge time, $\mathrm{m}(\mathrm{g})$ is the mass of active material and $\Delta \mathrm{V}$ is the width of the potential window for a full discharge.

The electrochemical characterization of the symmetrical SSCs was performed in a two-electrode configuration. The specific capacitance for the supercapacitors is calculated by $[4,5]$ :

$C_{s}=4 C(2)$

The energy density and power density of the supercapacitors are calculated according to $[4,5]$ :

$$
\begin{aligned}
& E=\frac{C(\Delta V)^{2}}{2} \times \frac{1000}{3600} \\
& P=\frac{E}{\Delta t} \times 3600
\end{aligned}
$$

where $\mathrm{E}\left(\mathrm{Wh} \cdot \mathrm{kg}^{-1}\right)$ is the energy density, $\mathrm{P}\left(\mathrm{W} \cdot \mathrm{kg}^{-1}\right)$ is the power density.

\section{Result And Discussion}




\subsection{Materials characterization}

Figure 1 show a diagram for the preparation of 3D porous carbon $\mathrm{P}$ from peanut shell. The peanut shell changed the color to a dark brown after immersing into $\mathrm{KOH}$ solution for $24 \mathrm{~h}$. After dried at $80^{\circ} \mathrm{C}$ for $6 \mathrm{~h}$, the dark yellow pieces were obtained. The dried mixture pieces were carbonized at $800^{\circ} \mathrm{C}$ for $1 \mathrm{~h}$ to obtain highly 3D porous carbon material (carbon $\mathrm{P}$ ). The process to synthesis 3D porous carbon $\mathrm{P}$ from peanut shell is low-cost, simple, and easy to set up for industry.

Figure 2a illustrates the Raman spectra of 3D porous carbon P, indicating two peaks containing the $\mathrm{D}$ and $\mathrm{G}$ bands at about 1328 and $1590 \mathrm{~cm}^{-1}$, respectively, in the carbon material. The $\mathrm{G}$ band is the bond stretch of $\mathrm{sp}^{2}$ bonded carbon atoms of $2 \mathrm{D}$ hexagonal lattice, and $\mathrm{D}$ band is caused by the lattice disorder in carbon structure $[4,9]$. The XRD pattern of the 3D porous carbon powder has two diffraction peaks (Fig. $2 \mathrm{~b}$ ), around $24^{\circ}(002)$ and $43^{\circ}(001)$, which reflect for a graphitic carbon phase and a disordered carbon layer [16-18]. The broad peak at around $24^{\circ}$ indicates that $3 \mathrm{D}$ porous carbon $\mathrm{P}$ powder is nearly amorphous phase [16]. In addition, the visible peak at $43^{\circ}$ can be clearly shown an interlayer condensation in graphitic carbon structure. To investigate the porous structure of 3D porous carbon $\mathrm{P}$, it was tested by nitrogen adsorption-desorption isotherm measurement (Figs. 2c, d). The 3D porous carbon $P$ powder exhibits an excellent specific surface area of $1348 \mathrm{~m}^{2} \mathrm{~g}^{-1}$ which much higher than carbon black $\left(50 \mathrm{~m}^{2} \mathrm{~g}^{-1}\right)$ and charcoal activated $\left(889 \mathrm{~m}^{2} \mathrm{~g}^{-1}\right)$ which shows in Fig. 2c. Herein, from Fig. 2c, the increase of the nitrogen isotherm plots at the high relative pressure suggest the presence of macropores while the small open hysteresis loops correspond to the existence of the mesopores. Figure $2 \mathrm{~d}$ shows the pore size distribution of all three samples. The carbon $\mathrm{P}$ samples show an adsorption average pore width of $1.94 \mathrm{~nm}$, while it is $11.98 \mathrm{~nm}$ for carbon black and $2.72 \mathrm{~nm}$ for charcoal. Moreover, the carbon $P$ produces a BJH Adsorption average pore diameter of $2.68 \mathrm{~nm}$, indicating that it is better than carbon black (30.73 nm) and charcoal $(5.20 \mathrm{~nm})$ (supporting information file, part 1).

From this result, 3D porous carbon $\mathrm{P}$ exhibits highly specific area which could be due to well pretreatment with $\mathrm{KOH}$ and suitable carbonization temperature $\left(800^{\circ} \mathrm{C}\right)$. More information of BET was introduced in supporting information file. The carbonization reaction with $\mathrm{KOH}$ provides the good environment for creating porous structure, making abundant mesoporous pore which distributed evenly in the samples [8].

The functional group and structure determination of organic compound and chemical group in 3D porous carbon P powder were determined via FTIR spectroscopy and the result is shown in Fig. 3a. The absorption broad peak at $3600-3200 \mathrm{~cm}^{-1}$ corresponds to the stretch of $-\mathrm{OH}$ [16]. Peak at $1251-1180$ $\mathrm{cm}^{-1}$ is observed due to $\mathrm{C}-\mathrm{C}$ stretching [17]. Peak at $1620-1564 \mathrm{~cm}^{-1}$ is related to vibration absorption of $\mathrm{C}=\mathrm{O}$ group [16]. Two peaks at 2924 and $2850 \mathrm{~cm}^{-1}$ are attributed to $\mathrm{C}-\mathrm{H}$ stretches [33]. Figure $3 \mathrm{~b}$ illustrates a TGA curve to measure the mass change of material through the increasing temperature. When the temperature increases from 50 to $400^{\circ} \mathrm{C}, 12.42 \mathrm{wt} \%$ weight loss is observed corresponding to the removal of surface and lattice-containing adsorbed water. The weight is loss about $83.33 \mathrm{wt} \%$ while the temperature increased from 400 to $800^{\circ} \mathrm{C}$, indicating the full decomposition and carbonization 
processes [32]. Figures 3(c, d) depict XPS spectra of the carbon $P$, indicating that the $C$ and $O$ elements appear in functional groups. The $\mathrm{C} 1 \mathrm{~s}$ spectrum of carbon $\mathrm{P}$ (Fig. 3c) can be deconvoluted into four peaks: C-C (284.7 eV), C-O (286.3 eV), C = O (289.2 eV) and O-C = O (287.7 eV) [6, 9]. The O 1s (Fig. 3d) core level spectrum shows two peaks at 531.7 and $533 \mathrm{eV}$ which can be assigned to $\mathrm{C}=\mathrm{O}$ (ester or carboxyl groups) and C-O (carbonyl group), respectively $[9,19]$. In additional, highly porous carbon materials derived from peanut shells has oxygen element in functional groups of carbon-oxygen not only increase an active surface but also can make a good effect to enhance the electrochemical capacitance $[4,5,20]$.

The surface morphology of the 3D porous carbon $\mathrm{P}$ was observed by SEM and the result is depicted in Figs. 4(a-d). It is clearly seen that the 3D porous carbon $\mathrm{P}$ has porous structure with high rough surface via the SEM images, which provides high surface area as well as ion transport layer for electrolyte ion diffusion and is suitable for electrode applications [5]. After carbonization with $\mathrm{KOH}$ as chemical activation, the uniform cellulose structure of peanut shells was broken to make a large amount of pores with micro and mesoporous sizes. Furthermore, at the high resolution of SEM measurement in Fig. 4d, the pore wall networks show high uniform rough surfaces. It is clearly seen that, the uniform rough surface of pore walls demonstrates the highly porous micro-structure which agrees with the value of specific surface area $\left(1348 \mathrm{~m}^{2} \mathrm{~g}^{-1}\right)$. In Fig. $4 \mathrm{~d}$, the walls are very rough which demonstrate the high specific surface area [5]. So far, the detailed microstructure and morphology of 3D porous carbon $\mathrm{P}$ powder also depict in TEM images of Figs. $4(\mathrm{e}, \mathrm{f}, \mathrm{g})$ and Fig. 5. The high resolution of carbon $\mathrm{P}$ via SEM images illustrates porous structure overlapping in interconnection with a highly uniform structure [19]. Moreover, the TEM images depict the existence of graphitic phase in carbon $\mathrm{P}$ sample which agree with XRD pattern. The edge layer of porous carbon $\mathrm{P}$ shows a short ordered lattice fringes which indicate the existence of graphitic structure in amorphous region. The combination between high concentrations of amorphous phase (Fig. 5) with low concentrations of crystalline phase can help to improve the capability and also the active surface area of electrode. Moreover, the HRTEM images revealed that 3D porous carbon $\mathrm{P}$ is an amorphous structure with worm-like micropores on the pore wall which can not only provide the abundant pools for electrolyte ions but also enhance the performance by improving diffusion kinetics during charge-discharge process. To obtain more morphology information of the highly porous structure of 3D porous carbon $\mathrm{P}$, the SEM high resolution was simulated using the programming language Python (Electronic Supplementary Video 1) that would function as an excellent electrolyte reservoir.

\subsection{Electrochemical properties}

\section{Three electrode system}

Figure 7 Electrochemical properties of the 3D porous carbon P: (a) CV curves, (b) GCD, (c) specific capacitance versus current density, (d) Ragone plot.

Figure 7 depicts the electrochemical performance of 3D porous carbon $P$ electrode in $1 \mathrm{M} \mathrm{Li}_{2} \mathrm{SO}_{4}$ aqueous electrolyte. The CV curves from 10 to $200 \mathrm{mV} \mathrm{s}^{-1}$ (Fig. 7a) display the symmetrical shape over the axis, indicating good capacitive behavior. At low scan rate, the CV curves exhibit the rectangular 
shape, and the CV curves become lozenge shape at high scan rate due to internal resistance and pores size distribution of carbon electrode [12,13]. Moreover, the shapes of CV curves are similar from low to high scan rate, indicating excellent ion transport between interfaces of electrolyte/electrode. Furthermore, the excellent stability of carbon P electrode is demonstrated by GCD curves at various current densities from 12 to $2 \mathrm{~A} \mathrm{~g}^{-1}$ (Fig. 7b) which show almost maintained the similar shape in the potential window from 0 to $1 \mathrm{~V}$. The specific capacitances of carbon $\mathrm{P}$ electrode increase gradually with a decrease of current density, illustrating good rate capability [23]. The GCD curves are not excellent symmetrical triangle at low scan rate of current density due to the porous structure of carbon $\mathrm{P}$ electrode material provides wormhole winding pathways for electron transport and a pseudocapacitive behavior of carbon $\mathrm{P}$ electrode [28, 30]. Even the GCD at high current density of $12 \mathrm{~A} \mathrm{~g}^{-1}$, the specific capacitance reaches the value of $156 \mathrm{~F} \mathrm{~g}^{-1}$ while the activated charcoal and carbon black electrode could not work at same current density (Fig. S3). As compared with its specific capacitance at $3 \mathrm{~A} \mathrm{~g}^{-1}$, the capacitance of carbon P electrode still exhibit $297 \mathrm{~F} \mathrm{~g}^{-1}$, which is much higher than carbon black electrode $\left(44 \mathrm{~F} \mathrm{~g}^{-1}\right)$ and charcoal $\left(148 \mathrm{~F} \mathrm{~g}^{-1}\right)$. The energy density and power density were calculated based on charge-discharge process and shown in Fig. $9 \mathrm{~d}$. It can be seen that the power density of carbon P electrode better than those of charcoal and carbon black at the same energy density. The carbon P electrode exhibits a high energy density of $53.61 \mathrm{Wh} \mathrm{kg}^{-1}$ compared with $20.56 \mathrm{~W} \mathrm{~kg}^{-1}$ of charcoal and $9.17 \mathrm{~W} \mathrm{~kg}^{-1}$ of carbon black at the same power density of $1000 \mathrm{~W} \mathrm{~kg}^{-1}$. The carbon black electrode and charcoal are shown some draw back, including the limited charge-discharge ability under high current density and also they have low power density. For comparison, Table 1 is listed the performance of electrode materials derived from biomass sources from some literatures. In general, the 3D porous carbon $\mathrm{P}$ material demonstrates a promising material with excellent conductivity and highly porous structure which suitable for electrode material of supercapacitors. Based on the examination of 3D porous carbon $\mathrm{P}$ in various electrolytes, further deeply study of carbon P material as electrode supercapacitors for the symmetrical solid-state supercapacitors has been investigated in next part.

\section{Symmetrical solid state supercapacitors (SSCs)}

Figure 8a shows the CV curve of symmetrical solid state supercapacitors (SSCs) based on carbon $\mathrm{P}$ electrode material. The $\mathrm{CV}$ curves has typical rectangular shape from -0.5 to $0.5 \mathrm{~V}$ at the scan rate in range of $5-100 \mathrm{mV} \mathrm{s}^{-1}$, indicating stable ion diffusion and good charge movement in the porous electrode layer. It is illustrated that the carbon $\mathrm{P}$ materials exhibited good electrochemical behavior suitable working as supercapacitors electrode [15]. As shown in Fig. 8b, the SSCs made by carbon P exhibits a low internal resistance around $3.88 \Omega$, illustrates a good contact of interface layer between substrate and electrode material and also electrode and electrolyte interface layer $[4,26,28]$. The lower internal resistance is allowed to better ionic diffusion into electrode layer which attributed to the high specific capacitance. The GCD curves of the SSCs at various current densities are depicted in Fig. 8c. It illustrates the maintained triangular shape which indicates that the balance of charge and discharge time, and also the stability of electrode layer during charge-discharge process. The specific capacitances

of SSCs increase with a decrease of current density, the specific capacitance is around $96 \mathrm{~F} \mathrm{~g}^{-1}$ at current 
density of $3 \mathrm{~A} \mathrm{~g} \mathrm{~g}^{-1}$ and reaches the highest of $116 \mathrm{~F} \mathrm{~g}^{-1}$ at $0.5 \mathrm{~A} \mathrm{~g}^{-1}$. The specific capacitance of SSCs at various current densities is shown in Fig. 8d. The decrease of current density leads to increase the specific capacitance is evident.

The Ragone plot of the symmetrical SSCs using 3D porous carbon P electrode is displayed in Fig. 9a. The SSCs device shows the good power density at high energy density. It indicates the maximum energy density of $9.06 \mathrm{Wh} \mathrm{kg}^{-1}$ at power density of $380 \mathrm{~W} \mathrm{~kg}^{-1}$. The power density increases to reach maximum value of $1500 \mathrm{~W} \mathrm{~kg}^{-1}$ at energy density of $7.5 \mathrm{Wh} \mathrm{kg}^{-1}$. The cycle stability of SSC is examined by chargedischarge measurement at $2 \mathrm{~A} \mathrm{~g}^{-1}$ and depicted in Fig. 9b. The specific capacitance of the symmetrical SSCs is maintained about $89 \%$ after 7000 charge-discharge cycles, which illustrates the stability of SSCs. The symmetrical SSCs have highly ability and high specific capacitance, there is only one symmetrical SSCs device $(1 \times 2 \mathrm{~cm})$ can operate on one red LED and a small motor (inset figure in Fig. $9 \mathrm{~b}$ and Electronic Supplementary Video 2). 
Table 1

The comparison of biomass-derived carbon materials for three electrode system

\begin{tabular}{|c|c|c|c|c|}
\hline Biomass source & $\begin{array}{l}\text { Specific surface area } \\
\left(\mathrm{m}^{2} \mathrm{~g}^{-1}\right)\end{array}$ & Electrolyte & $\begin{array}{l}\text { Specific capacitance } \\
\left(\mathrm{F} \mathrm{g}^{-1}\right)\end{array}$ & Ref. \\
\hline Pomelo peel fiber & 38.44 & $\mathrm{KOH} 6 \mathrm{M}$ & 222.6 & 6 \\
\hline Willow catkins & 1775.7 & $\mathrm{KOH} 6 \mathrm{M}$ & 292 & 8 \\
\hline Walnut shell & 62 & $\mathrm{KOH} 1 \mathrm{M}$ & 255 & 9 \\
\hline Silkworm cocoon & 3386 & $\mathrm{TEABF}_{4} / \mathrm{AN} 1 \mathrm{M}$ & 263.5 & 10 \\
\hline Natural cotton & 2436 & $\mathrm{KOH} 6 \mathrm{M}$ & 283 & 11 \\
\hline Bagasse & 1892.4 & $\mathrm{KOH} 6 \mathrm{M}$ & 268.4 & 12 \\
\hline Cherry stone & 1300 & $\mathrm{H}_{2} \mathrm{SO}_{4} 2 \mathrm{M}$ & 230 & 14 \\
\hline Sugarcane bagasse & 805.58 & $\mathrm{KOH} 6 \mathrm{M}$ & 323 & 21 \\
\hline Coffee bean & 763 & $\mathrm{H}_{2} \mathrm{SO}_{4} 1 \mathrm{M}$ & 180 & 22 \\
\hline Melaleuca barks & 1714 & $\mathrm{H}_{2} \mathrm{SO}_{4} 1 \mathrm{M}$ & 233 & 24 \\
\hline Rice husk & 786.15 & $\mathrm{KOH} 6 \mathrm{M}$ & 260 & 25 \\
\hline Pine cone & 1515 & $\mathrm{Na}_{2} \mathrm{SO}_{4}$ & 137 & 26 \\
\hline Used Cattail & 1951 & $\mathrm{KOH} 6 \mathrm{M}$ & 336 & 29 \\
\hline Sugarcane bagasse & 1260 & $\mathrm{H}_{2} \mathrm{SO}_{4} 1 \mathrm{M}$ & 280 & 30 \\
\hline Waste paper & 416 & $\mathrm{KOH} 6 \mathrm{M}$ & 180 & 31 \\
\hline Peanut shell & 1348 & $\mathrm{Li}_{2} \mathrm{SO}_{4} 1 \mathrm{M}$ & 386 & This work \\
\hline
\end{tabular}

\section{Conclusions}

In summary, the 3D porous carbon P materials derived from peanut shell as the electrodes of the symmetrical SSCs were successfully demonstrated in this study. The 3D porous carbon $\mathrm{P}$ with mesoporous pores exhibited poorly crystalline structure and high specific surface area of $1348 \mathrm{~m}^{2} \mathrm{~g}^{-1}$. It had the maximum specific capacitance of $386 \mathrm{~F} \mathrm{~g}^{-1}$ which higher than commercial charcoal $\left(148 \mathrm{~F} \mathrm{~g} \mathrm{~g}^{-1}\right)$ and carbon black electrode $\left(66 \mathrm{~F} \mathrm{~g}^{-1}\right)$ at the same current density of $2 \mathrm{~A} \mathrm{~g}^{-1}$, and possessed energy density and power density of $53.61 \mathrm{Wh} \mathrm{kg}^{-1}$ and $1000 \mathrm{~W} \mathrm{~kg}^{-1}$, respectively. The symmetrical SSCs using 3D porous carbon $P$ electrodes and GPE of PVA-KOH exhibited the specific capacitance of $116 \mathrm{~F} \mathrm{~g}^{-1}$ at $0.5 \mathrm{~A} \mathrm{~g}^{-1}$, energy density and power density of $9 \mathrm{Wh} \mathrm{kg}^{-1}$ and $380 \mathrm{~W} \mathrm{~kg}^{-1}$, respectively, and cycling 
stability with $89 \%$ retention after 7000 cycles. The 3D porous carbon $\mathrm{P}$ has high potential application for making energy storage devices.

\section{Declarations}

Acknowledgement 'Not applicable'

\section{Authors' contributions}

P. A. Le, Viet Bac Thi Phung and Trong Nghia Nguyen designed the work, P. A. Le, Van Qui Le carried out the experiment and analyzed the data. P. A. Le wrote the manuscript. All authors read and approved the final manuscript.

Funding 'Not applicable'

\section{Availability of data and materials}

All data are fully available without restriction.

\section{Ethics approval and consent to participate}

No animal, human subjects and harmful chemical were used in this work.

\section{Consent for publication}

This manuscript does not contain any individual person's data.

\section{Competing interests}

There is no competing interest.

\section{References}

[1] N. T. Nguyen, P. A. Le, V. B. T. Phung, Biomass-derived carbon hooks on Ni foam with free binder for high performance supercapacitor electrode, Chemical Engineering Science, 2021, 229, 116053.

[2] J. Zhu, C. Yan, X. Zhang, C. Yang, M. Jiang, X. Zhang, A sustainable platform of lignin: From bioresources to materials and their applications in rechargeable batteries and supercapacitors, Progress in Energy and Combustion Science, 2020, 76, 100788.

[3] T. N. Nguyen, P. A. Le, V. B. T. Phung, Facile green synthesis of carbon quantum dots and biomassderived activated carbon from banana peels: synthesis and investigation, Biomass Conv. Bioref., 2020.

[4] P. A. Le, V. T. Nguyen, P. J. Yen, T. Y. Tseng, K. H. Wei, A new redox phloroglucinol additive incorporated gel polymer electrolyte for flexible symmetrical solid-state supercapacitors, Sustainable Energy Fuels, 
[5] P. A. Le, V. T. Nguyen, S. K. Sahoo, T. Y. Tseng, K. H Wei, Porous carbon materials derived from areca palm leaves for high performance symmetrical solid-state supercapacitors, Journal of Materials Science, 2020.

[6] J. Li, W. Liu, D. Xiao, X. Wang, Oxygen-rich hierarchical porous carbon made from pomelo peel fiber as electrode material for supercapacitor, Applied Surface Science, 2017, 416, 918-924. [7] H. Yin, B. Lu, Y. Xu, D. Tang, X. Mao, W. Xiao, D. Wang, A. N. Alshawabkeh, Harvesting Capacitive Carbon by Carbonization of Waste Biomass in Molten Salts, Environ. Sci. Technol. 2014, 48, 8101-8108.

[8] L. Xie, G. Sun, F. Su, X. Guo, Q. Kong, X. Li, X. Huang, L. Wan, W. Song, K. Li, C. Lv, C. M. Chen, Hierarchical porous carbon microtubes derived from willow catkins for supercapacitor applications, $\mathrm{J}$. Mater. Chem. A, 2016, 4, 1637-1646.

[9] X. Xu, J. Gao, Q. Tian, X. Zhai, Y. Liu, Walnut shell derived porous carbon for a symmetric all-solid-state supercapacitor, Applied Surface Science, 2017, 411, 170-176.

[10] J. Sun, J. Niu, M. Liu, J. Ji, M. Dou, F. Wang, Biomass-derived nitrogen-doped porous carbon with tailored hierarchical porosity and high specific surface area for high energy and power density supercapacitor, Applied Surface Science, 2018, 427, 807-813.

[11] P. Cheng, T. Li, H. Yu, L. Zhi, Z. Liu, Z. Lei, Biomass-derived carbon fiber aerogel as a binder-free electrode for high-rate supercapacitor, J. Phys. Chem. C, 2016, 120, 2079-2086.

[12] P. Hao, Z. Zhao, J. Tian, H. Li, Y. Sang, G. Yu, H. Cai, H. Liu, C. P. Wong, A. Umar, Hierarchical porous carbon aerogel derived from bagasse for high performance supercapacitor electrode, nanoscale, 2014, 6, $12120-12129$.

[13] S. T. Senthilkumar, R. Kalai Selvan, J. S. Melo, C. Sanjeeviraja, High performance Solid-State Electric Double Layer Capacitor from Redox Mediated Gel Polymer Electrolyte and Renewable Tamarind Fruit Shell Derived Porous Carbon, ACS Appl. Mater. Interfaces, 2013, 5, 10541-10550.

[14] M. O. Marín, J. A. Fernández, M. J. Lázaro, C. F. González, A. M. García, V. G. Serrano, F. Stoeckli, T. A. Centeno, Cherry stone as precursor of activated carbons for supercapacitor, Mater Chem. Phys., 2009, $114,323-327$.

[15] L. Wang, Y. Zheng, Q. Zhang, L. Zuo, S. Chen, S. Chen, H. Hou, Y. Song, Template-free synthesis of hierarchical porous carbon derived from low-cost biomass for high performance supercapacitor, RSC Adv., 2014, 4, 51072-51079.

[16] M. Dhelipan, A. Arunchander, A. K. Sahu, D. Kalpana, Activated carbon from orange peels as supercapacitor electrode and catalyst support for oxygen reduction in proton exchange membrane fuel cell, Journal of Saudi Chemical Society, 2017, 21, 487-494. 
[17] H. Shang, Y. Lu, F. Zhao, C. Chao, B. Zhang, and H. Zhang, Preparing high surface area porous carbon from biomass by carbonization in a molten salt medium, RSC Adv., 2015, 5, 75728-75734.

[18] N. Sudhan, K. Subramani, M. Karnan, N. Ilayaraja, and M. Sathish, Biomass-derived activated porous carbon from rice straw for a high-energy symmetric supercapacitor in aqueous and non-aqueous electrolyte, Energy Fuels, 2017, 31, 977-985.

[19] F. Ma, J. Wan, G. Wu and H. Zhao, Highly porous carbon microflakes derived from catkins for highperformance supercapacitor, RSC Adv., 2015, 5, 44416-44422.

[20] F. Sun, J. Gao, Y. Zhu, X. Pi, L. Wang, X. Liu, Y. Qin, A high performance lithium ion capacitor achieved by the intergration of a Sn-C anode and a biomass-derived microporous activated carbon cathode, Sci Rep., 2017, 7, 40990.

[21] J. Liu, Y. Deng, X. Li, L. Wang, Promising nitrogen-rich porous carbons derived from one-step calcium chloride activation of biomass-based waste for high performance supercapacitors, ACS Sustainable Chem. Eng., 2016, 4, 177-187.

[22] C. Huang, T. Sun, D. H. Jurcakova, Wide electrochemical window of supercapacitor from coffee beanderived phosphorus-rich carbon, ChemSusChem, 2013, 6, 2330-2339.

[23] Y. Zhang, F. Wang, H. Zhu, L. Zhou, X. Zheng, X. Li, Z. Chen, Y. Wang, D. Zhang, D. Pan, Preparation of nitrogen-doped biomass-derived carbon nanofibers/graphene aerogel as a binder-free electrode for high performance supercapacitor, Applied Surface Science, 2017, 426, 99-106.

[24] Q. P. Luo, L. Huang, X. Gao, Y. Cheng, B. Yao, Z. Hu, J. Wan, X. Xiao, J. Zhou, Activated carbon derived from melaleuca barks for outstanding high-rate supercapacitor, Nanotechnology, 2015, 26, 304004.

[25] Y. Huang, J. He, Y. Luan, Y. Jiang, S. Guo, X. Zhang, C. Tian, B. Jiang, Promising biomass-derived hierarchiral porous carbon material for high performance supercapacitor, RSC Adv., 2017, 7, 1038510390.

[26] A. Bello, N. C. Manyala, F. Barzegar, A. A. Khaleed, D. Y. Momodu, J. K. Dangbegnon, Renewable pine cone biomass derived carbon materiaks for supercapacitor application, RSC Adv., 2016, 6, 1800-1809.

[27] L. L. Zhang, Y. Gu, X. S. Zhao, Advanced porous carbon electrodes for electrochemical capacitor, J. Mater. Chem. A, 2013, 1, 9395-9408.

[28] J. Choi, M. Yang, S. K. Kim, Pseudocapacitive organic catechol derivative-functionalized threedimensional graphene aerogel hybrid electrodes for high-performance supercapacitor, Applied Surface Science, 2017, 422, 316-320.

[29] Z. Fan, D. Qi, Y. Xiao, J. Yan, T. Wei, One-step synthesis of biomass-derived porous carbon foam for high performance supercapacitors, Materials Letters, 2013, 101, 29-32. 
[30] M. Wahid, D. Puthusseri, D. Phase, S. Ogale, Enhanced Capacitance Retention in a Supercapacitor Made of Carbon from Sugarcane Bagasse by Hydrothermal Pretreatment, Energy Fuels, 2014, 28, 42334240.

[31] D. Kalpana, S. H. Cho, S. B. Lee, Y. S. Lee, R. Misra, N. G. Renganathan, Recycled waste paper-A new source of raw material for electric double-layer capacitors, Journal of Power Sources, 2009, 190, 587591.

[32] M. Wang, W. Wang, W. Wang, X. Guo, Synthesis of partially graphitic nanoflake-like carbon/ $/ \mathrm{Fe}_{3} \mathrm{O}_{4}$ magnetic composites from chitosan as high-performance electrode materials in supercapacitors, RSC Adv., 2014, 4, 39625-39633.

[33] L. I. Nasibulina, I. V. Anoshkin, A. G. Nasibulin, A. Cwirzen, V. Penttala, E. I. Kauppine, Effect of Carbon Nanotube Aqueous Dispersion Quality on Mechanical Properties of Cement Composite, Journal of Nanomaterials, 2012, 6 pp.

\section{Supplemental Note}

Electronic Supplementary Videos 1 and 2 not available with this version

\section{Figures}

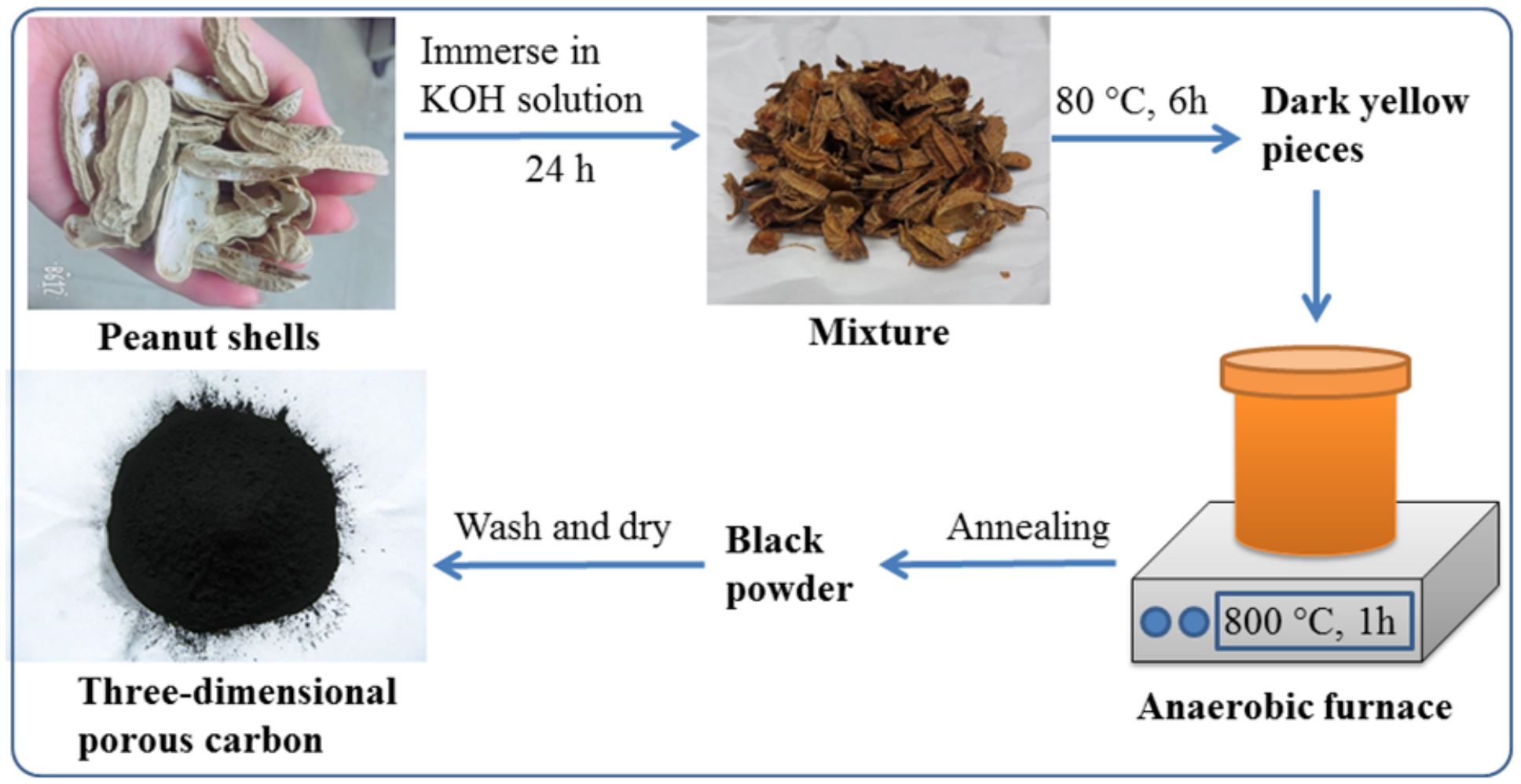

Figure 1 
Schematic of the synthesizing porous carbon from peanut shells.
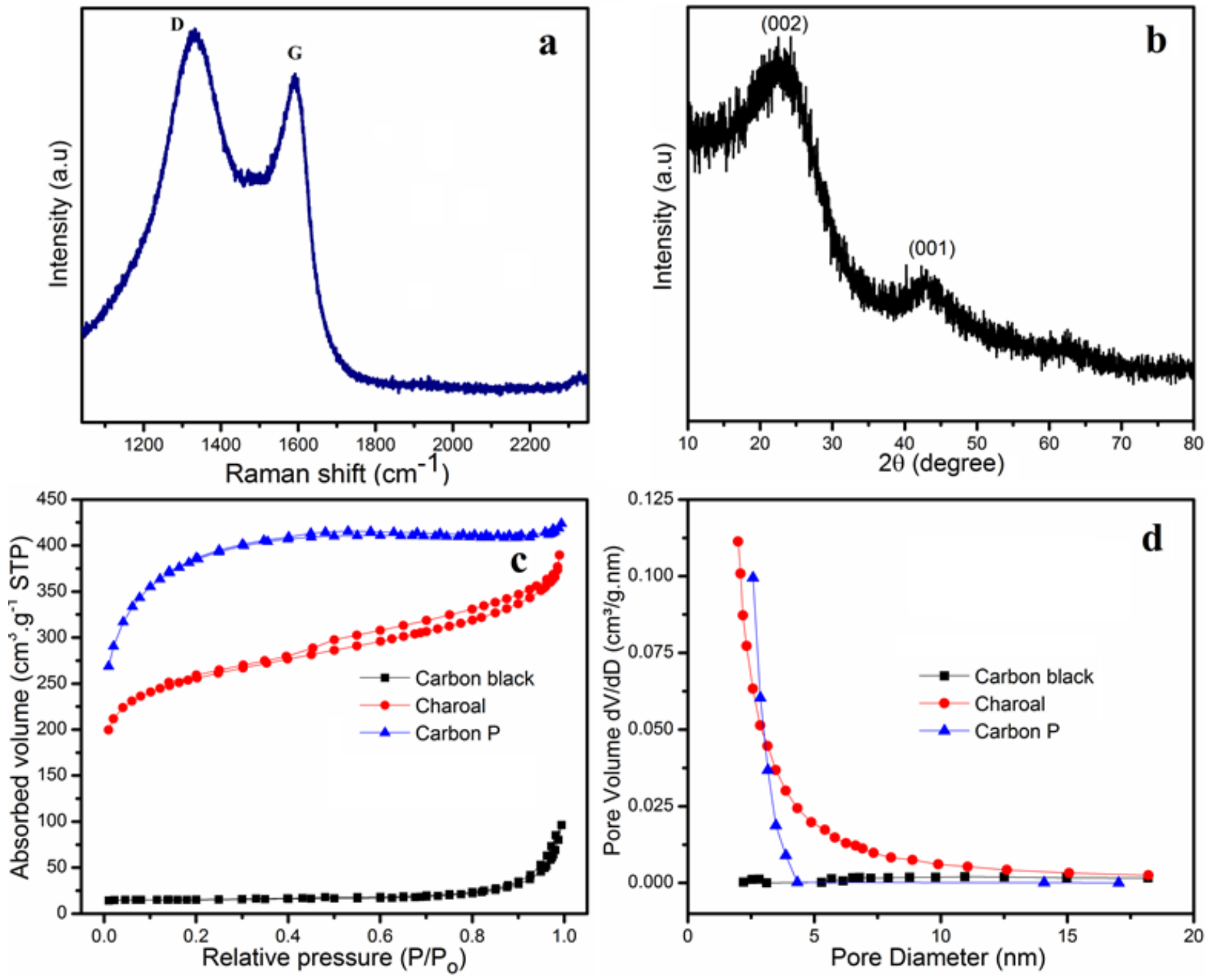

Figure 2

(a) Raman spectra, (b) XRD pattern of 3D porous carbon material, (c) Nitrogen absorption/desorption isotherm, and (d) pore size distributions of carbon black, charcoal and 3D porous carbon material. 

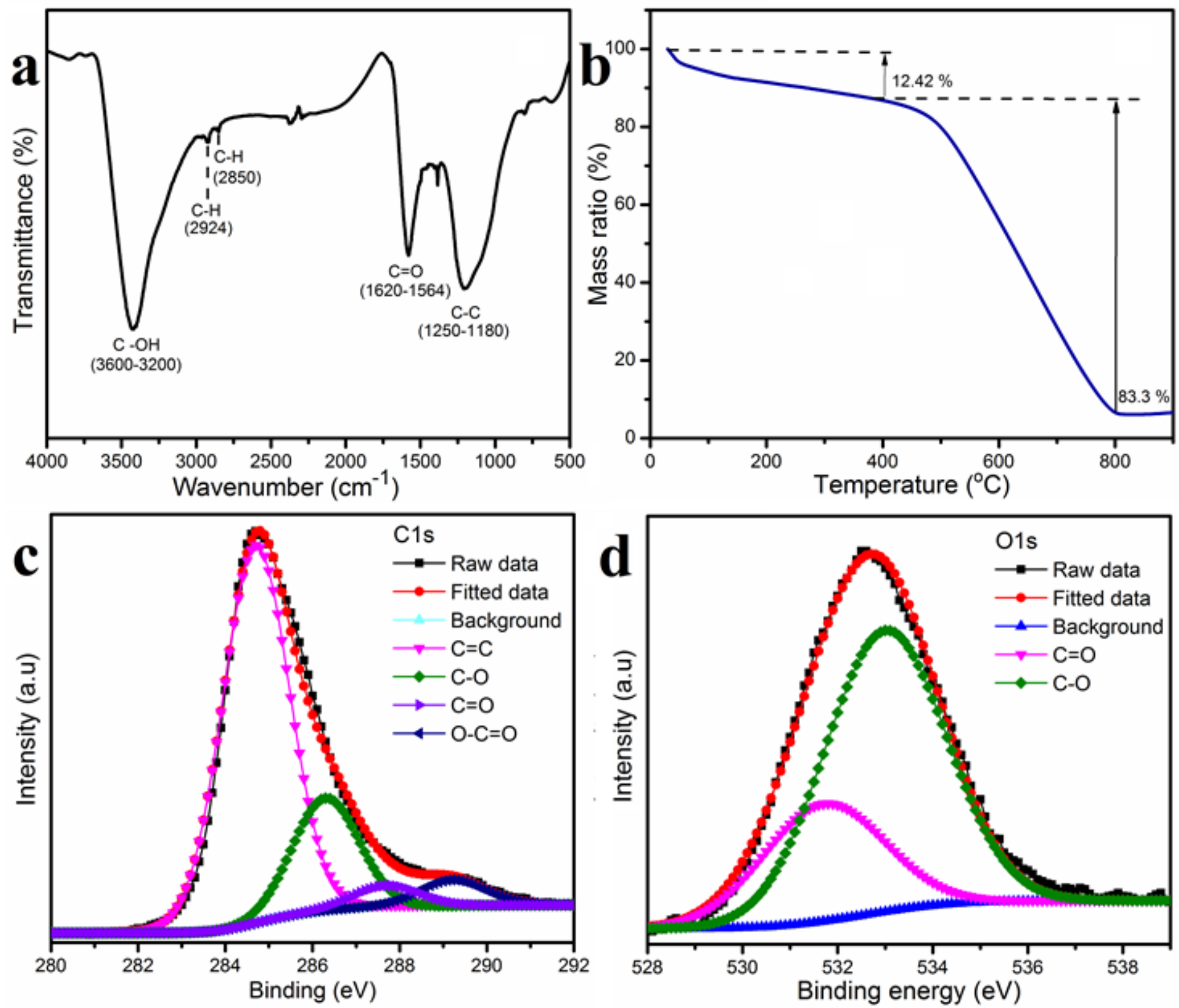

Figure 3

(a) FTIR and (b) TGA, (c, d) XPS spectra of the 3D porous carbon P. 


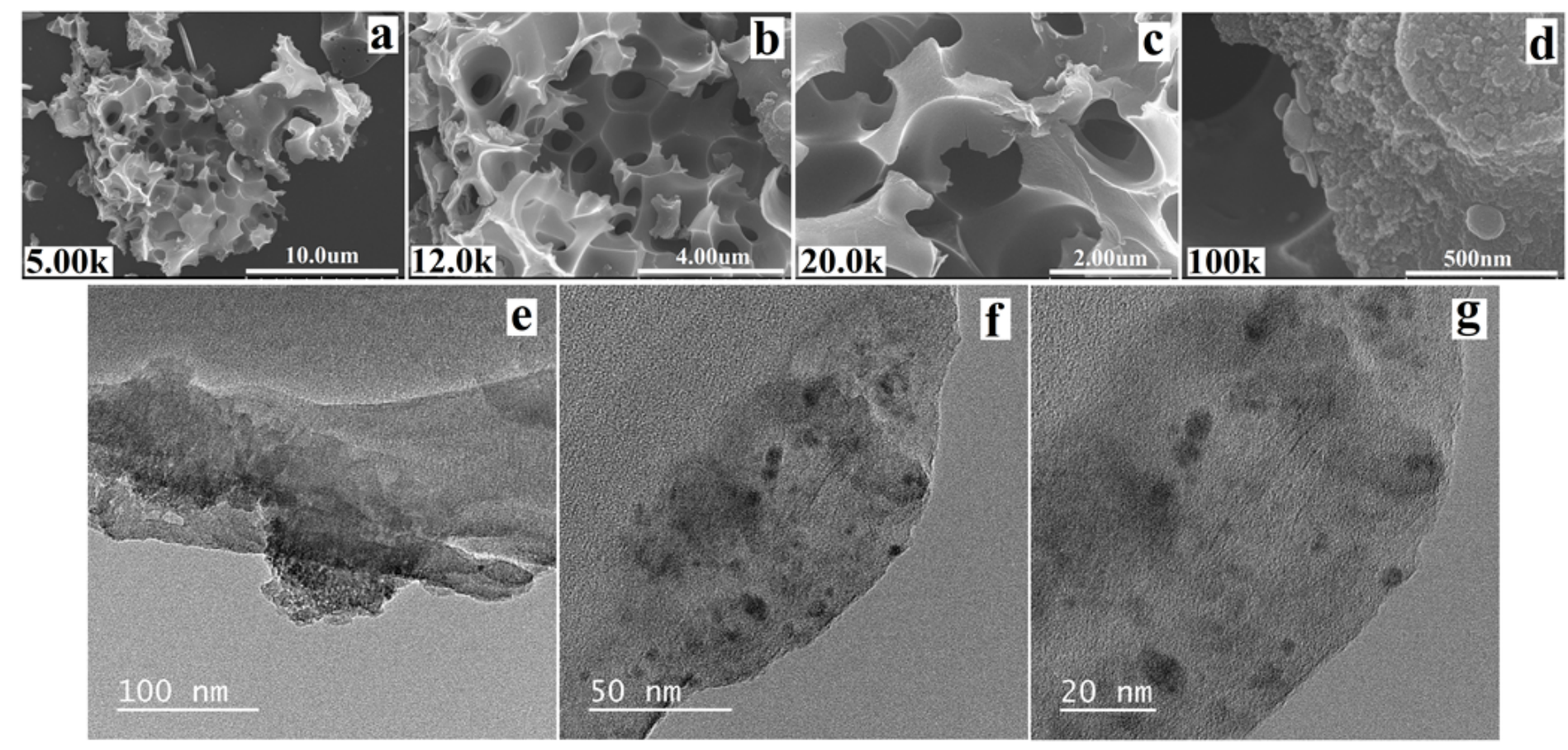

Figure 4

$(a, b, c, d)$ SEM and $(e, f, g)$ TEM images of 3D porous carbon $P$ at various magnifications.

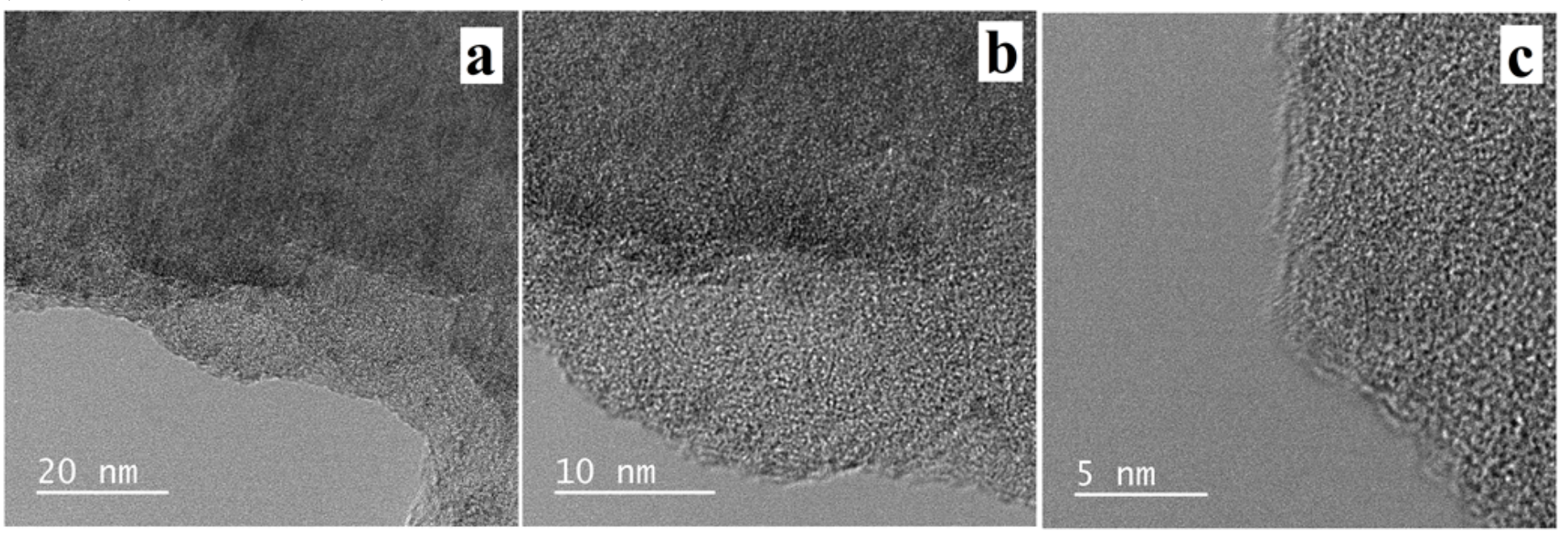

Figure 5

HRTEM images of peanut shell-derived porous carbon material. 

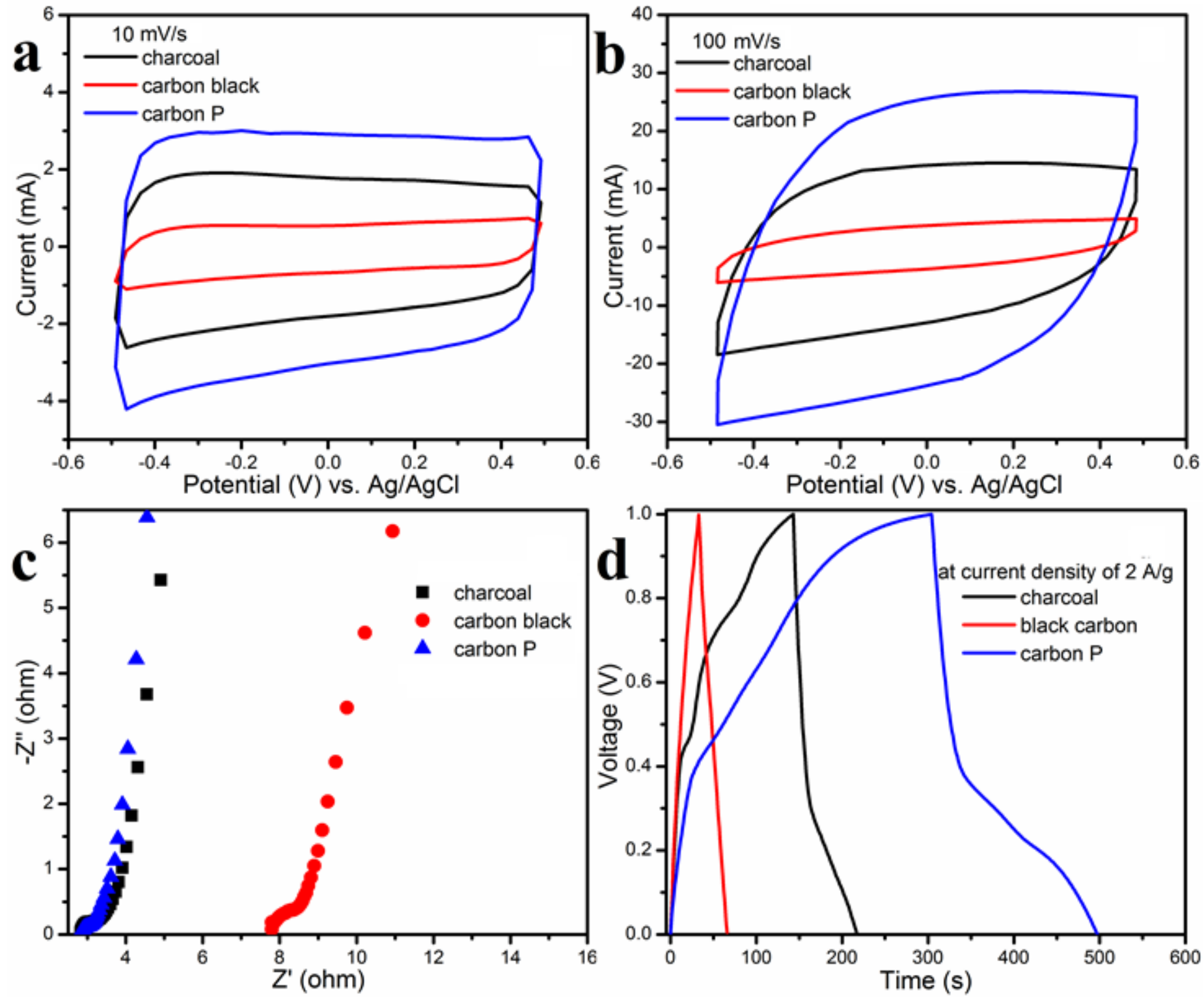

Figure 6

Electrochemical properties of the three materials in comparison: (a, b) CV curves, (c) EIS plots, (d) GCD curves. 

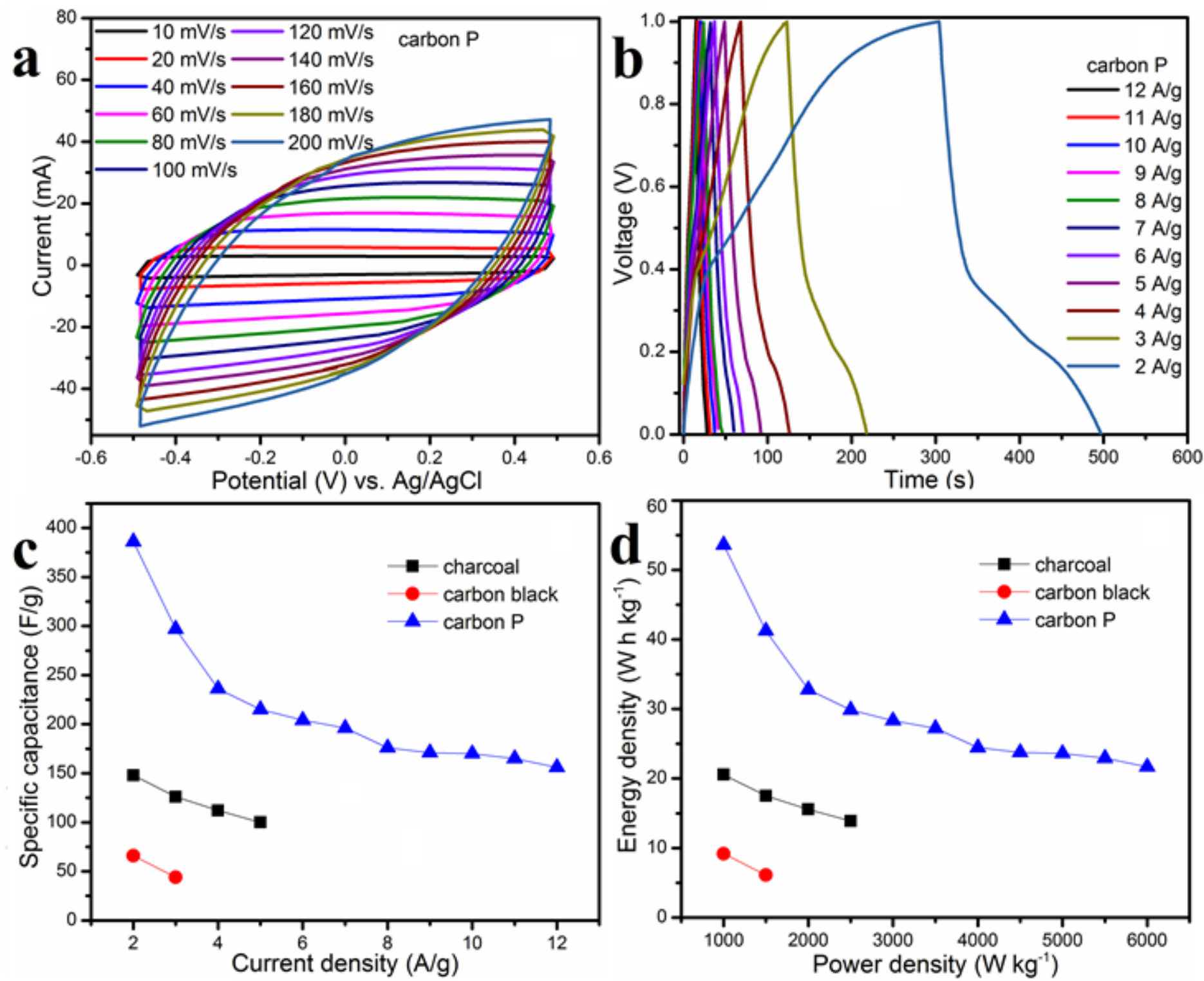

Figure 7

Electrochemical properties of the 3D porous carbon P: (a) CV curves, (b) GCD, (c) specific capacitance versus current density, (d) Ragone plot. 

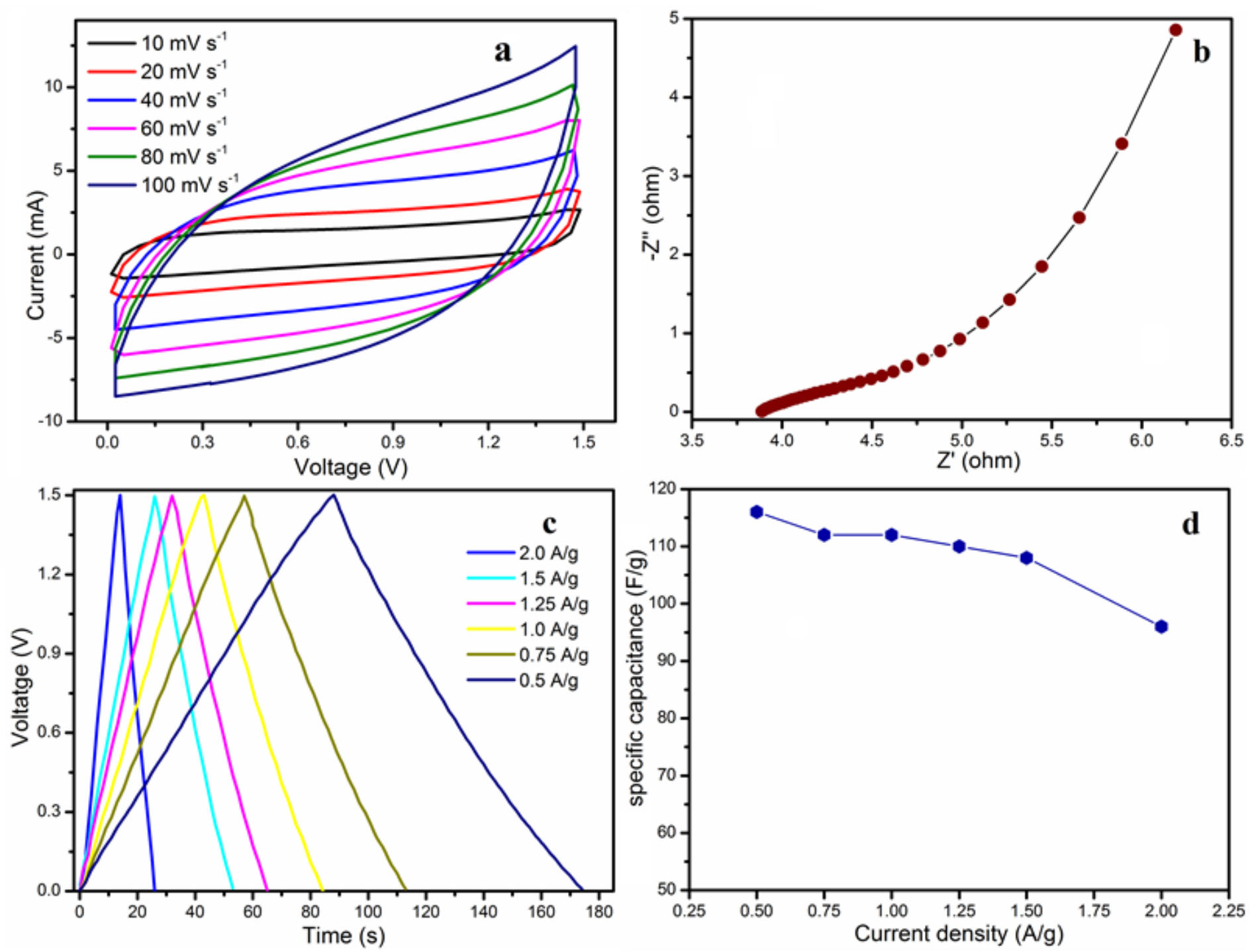

Figure 8

Electrochemical properties of SSCs: (a) CV curves, (b) Niquist plot, (c) GCD curves, and (d) specific capacitance versus current density. 

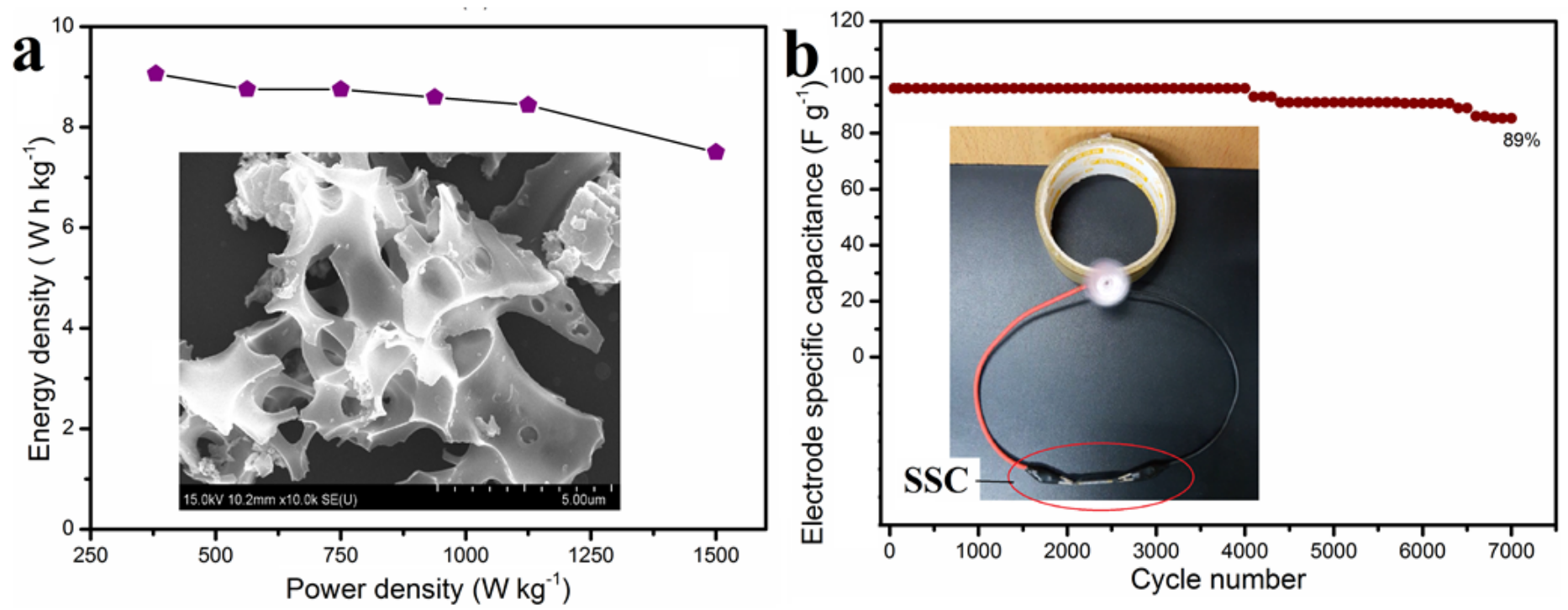

Figure 9

(a) Ragone plot of the symmetrical SSCs has highly porous carbon electrode. (b) The specific capacitance of the symmetrical SSCs at $2 \mathrm{~A} \mathrm{~g}-1$ after 7000 cycles.

\section{Supplementary Files}

This is a list of supplementary files associated with this preprint. Click to download.

- 2Graphicalabstract.docx

- 5Supportinginformation.docx 